\title{
Knowledge, Perceptions and Practices on Antiretroviral Therapy in Farming Communities in Ghana: A Study of HIV Positive Women
}

\author{
Daniel Boateng ${ }^{1}$, Dadson Awunyo-Vitor ${ }^{2, *}$ \\ ${ }^{1}$ Department of Community Health, School of Medical Sciences, Kwame Nkrumah University of Science and Technology \\ ${ }^{2}$ Department of Agricultural Economics, A gribusiness and Extension, Kwame Nkrumah University of Science and Technology, \\ Kumasi, Ghana
}

\begin{abstract}
Low levels of knowledge of antiretroviral therapy (ART) and Prevention of Mother-To-Child-Trans mission (MTCT) a mong persons living with HIV present an unwanted window for transmission within the general population. The purpose of this study is to assess the level of knowledge, attitudes and perceptions of HIV positive wo men on antiretroviral therapy (ART) and Prevention of Mother-To-Child-Transmission (MTCT). The study surveyed 211 HIV positive wo men from ART centres in two districts in Ashanti region of Ghana. Data was collected through interviews using structured questionnaires and focus group discussion using interview guides. Qualitative and quantitative techniques were used to analyze the data. The study revealed that about $15 \%$ of the women exhibited no knowledge about the possibility of transmission of HIV from mother to child whilst $36 \%$ had no knowledge on the mode of MTCT of HIV. Those who had knowledge of MTCT indicated that this could be intrauterine $(88 \%)$, delivery $(69 \%)$ and through breastfeeding ( $82 \%)$.Mothers with inco mprehensive knowledge on ART were 2.5 times more likely to default ART $(\mathrm{OR}=2.5, \mathrm{p}=0.002)$. Comprehensive knowledge was positively influenced by high education level $(\mathrm{OR}=1.9 ; \mathrm{p}=0.003)$. Social marketing campaigns should be developed and targeted at improving women literacy on their health issues and getting more women to test for HIV in order to incorporate them into PMTCT programmes. Further research however needs to be conducted to ascertain the facility and community based factors that influence the women's knowledge on ART and PMTCT.
\end{abstract}

Keywo rds HIV, Women, Knowledge, Perception, Ghana ART,PMTCT

\section{Introduction}

HIV/AIDS remain a major cause of death worldwide with the majority coming from sub-Saharan Africa. A IDS has killed more than 25 million people since 1981 and an estimated 33.2 million (31.4 million - 35.3 million) people are living with HIV/AIDS worldwide with 2.5 million of them from sub-Saharan Africa. In 2007, 2.1 million HIV related deaths were recorded with 1.6 million $(76 \%)$ from Sub Saharan Africa[13].

In Ghana, HIV prevalence a mong adults in 2010 was $1.5 \%$. An estimated 267,069 persons made up of 95,206 males and 126,735 females were living with HIV as at 2010 and the prevalence of HIV/AIDS among antenatal clients was $2.0 \%[14]$. Prevalence of HIV among ANC women is therefore $0.5 \%$ higher than prevalence among adults population and the estimated number of pregnant women

* Corresponding author:

Awunyovitor@yahoo.co.uk (Dadson Awunyo-Vitor)

Published online at http://journal.sapub.org/phr

Copyright (C) 2012 Scientific \& Academic Publishing. All Rights Reserved living with HIV in 2009 was 13,000. Currently, the Ashanti and Eastern regions are home to the greatest percentages of HIV positive people with prevalence of $3.2 \%$ and $3.0 \%$ respectively[15].

The HIV epidemic is becoming increasingly feminized with nearly $50 \%$ of people living with HIV being females globally as at 2010[20]. HIV remains the leading cause of death among women in reproductive age and HIV infection among children has mainly been through Mother-To-Child-Transmission (MTCT). However, the most effective way of preventing MTCT of HIV is to prevent infection in wo men of reproductive age.

As of December 2009, HIV testing and counselling services were accessed by $53 \%$ of all pregnant women in Ghana, $74 \%$ of whom were tested for HIV and given their results. The HIV prevalence among those tested was $1.7 \%$ of which $55 \%$ received antiretroviral drugs to prevent vertical transmission. The comparative proportion of babies born to HIV infected women who received antiretroviral drugs for prophylaxis was $30 \%$ [8].

The rapid incidence and fatality of HIV/AIDS g lobally with its greatest impact in sub-Saharan Africa has been a 
growing concern of world leaders and stakeholders in health to continuously seek a remedy to this canker. In the light of this, there have been International and national efforts to improve care and support for PLHIV, including HIV Testing and counselling (HTC) services, establishing ART centres and PMTCT services. Though awareness of HIV and AIDS have been high since 2003, where $98 \%$ of wo men and $99 \%$ of men were reportedly aware on HIV, comprehensive knowledge on HIV and AIDS, appropriate prevention and non-stigmatizing behaviour have been lagging behind[5]. As at $2007,25.1 \%$ of young women and $33 \%$ of young men aged 15-24 years had comprehensive knowledge (i.e. correctly identified ways of transmitting HIV and rejected misconception about HIV transmission) of HIV and AIDS. In 2008, the Ghana Demographic and Health Survey (GDHS) showed that only $28.3 \%$ of female respondents age $15-24$ and $34.2 \%$ of men had comprehensive knowledge about HIV and AIDS. There has thus been little progress along this front[8].

Patient's knowledge, attitudes and practices on HIV/AIDS, PMTCT and ARTs influence their motivation and uptake of ARVs for PMTCT. A good level of understanding about HIV by the patient, a belief that ART is effective and prolongs life, and recognition that poor adherence may result in viral resistance and treatment failure all impact favourably upon a patient's ability to adhere. Conversely, a lack of interest in becoming knowledgeable about HIV and a belief that ART may in fact cause harm adversely affect adherence[18]. A study in Uganda to find out the barriers to accessing Highly Active Antiretroviral Therapy (HAART) by HIV positive wo men, found out that women who had not enrolled in the (Highly Active Antiretroviral therapy) HAART-Plus programme had a remarkably lower level of knowledge on HIV/AIDS and HAART compared with those who had enrolled in the programme[4]. Other studies in the continent also found mothers knowledge on PMTCT to be low[1],[7].Ones knowledge of HIV, ART and PMTCT is however influenced by interp lay of socio economic and other cultural factors including clients' educational level and marital status. A lower level of general education and poorer literacy may impact negatively on some patients' ability to adhere, while a higher level of education has a positive impact[2]. The purpose of this study is to ass ess the level of knowledge, attitudes and perceptions of client's on ART and PMTCT and determine the extent of influence of client's knowledge level on accessing ART. Low levels of knowledge of HIV status among persons living with HIV present an unwanted window for transmission within the general population, in addition to sex with female sex workers, their clients, and non-paying partners [8].

\section{Methodology}

\subsection{Study Design}

The study was a descriptive cross sectional design. The methods were both qualitative and quantitative and data was collected at the individual and facility level.

\subsection{Study Area}

The study was conducted at the ART centres in two farming towns in the Ashanti Region, Ejura and Ny inahini. These are two farming dominated towns in the Ejura-Sekye dumasi and AtwimaMponua districts respectively. The agriculture sector in the Ejura-Sekyedumase District dominates all the other sectors of the economy in terms of emp loyment as a typical characteristic of a Ghanaian setting. It employs about $68.2 \%$ of the population which is above the national rate of $60 \%$.W ith respect to HIV prevalence, the Ashanti Region recorded the second highest in the country in $2011(3.0 \%)$. Routine HIV testing and counselling are offered during antenatal care visits for pregnant mothers at both ART centres.

\subsection{Sampling and Sample Size}

The sample was selected in two (2) stages. Two ART centres were purposively selected from two farming communities in the Ashanti Region. These were the Nyinahin Hospital and the Ejura District Hospital. Systematic random sampling was used to select respondents for exit interviews and FGDs at the ART centre. Admin istrative records, which included the pharmacy refill register, medical consultation appointment visits, were also used to get information of respondents. A total of 211 respondents were involved in the study.

\subsection{Data Collection and Tools}

The data collection technique for the quantitative method was interviews and the tool employed was structured questionnaires (open ended and closed). Qualitative data was obtained using semi-structured interviews, focus group discussions (FGDs) and interviews with key informants using tape recorders and interviews guides as data collection tools. Interviews and the FGD were carried out in quiet and discreet locations in a vacant room in the hospital's outpatient department. The interviews were conducted and audio-taped in the local language. Tapes were transcribed verbatim in Twi and then back-translated into English. Spot checks of interview and FGD transcripts and translations were regularly conducted to ensure the completeness of the transcription and the accuracy of the translation. Questionnaires and interview guides were pre-tested to check for clarity, consistency and acceptability of the questions to respondents. Following this, the necessary corrections were made and questionnaires finalized for the actual field work.

\subsection{Statistical Analysis}

All questionnaires and interview results from the field were checked for completeness and internal errors. Questionnaires were then sorted, numbered and kept in files labelled per facility from which the participants were 
interviewed.

Responses on the various questions to test for knowledge were coded as yes, no or don't know. General knowledge level was computed by respondents total correct responses from the various issues posed to test for knowledge. Respondents who accepted all correct respons es were groups having "adequate knowledge" and vice versa.

Bivariate associations and 95\% confidence intervals were used to access the influence of certain socio demographic characteristics on the knowledge level of the women using STATA 11

\subsection{Ethical Consider ation}

Ethical clearance for the study was obtained from the Committee on Human Research, Publications and Ethics (CHPRE) of the Kwame Nkrumah University of Science and Technology (KNUST) and Komfo Anokye Teaching Hospital (KATH). The partic ipant's capacity to consent was considered. There was full disclosure or discussion of relevant information/ questions. Translators were used for participants who could not read.

\section{Results and Discussion}

\subsection{Background Characteristics}

The research was conducted using 211 HIV positive women from ART centres at Ejura and Nyinahini in the Ashanti Region. One hundred and twenty one of the respondents representing $57 \%$ are from Nyinahini, and 90 (43\%) are from Ejura ART centre.

More than 50\% have been on treatment for less than 24 months with the maximum length on treatment being 156 months (figure 1). The mean and median length on treatment is 20 months and 21 months respectively. A regression analysis indicate a statistically significant association between one's months of being on ART and regularity at ART $(\mathrm{t}=3.91, \mathrm{p}=0.000)$.

Majority of the women aged below 35 years (55\%) and the mean age was 36 years $(\mathrm{SD}=8)$. Majority of the women were married and $13 \%$ had schooled to the secondary level with $35 \%$ having no formal education. Seventy-three percent with farming being the most cited job. In general, the defaulter rate was $21 \%$. Th is was incons istent with estimates of average rates of adherence to ART in many different social and cultural settings which range from $50 \%$ to $70 \%[11],[16],[18]$.
Table 1. Summary of Socio-demographic Characteristics

\begin{tabular}{|c|c|c|}
\hline Variables & Frequency & Percentage \\
\hline \multicolumn{3}{|l|}{ Age } \\
\hline $18-24$ & 46 & \\
\hline $25-34$ & 70 & 22 \\
\hline $35-44$ & 65 & 33 \\
\hline $44-49$ & 30 & 31 \\
\hline \multicolumn{3}{|l|}{ mean $=36, S D=8$} \\
\hline \multicolumn{3}{|l|}{ Marital status } \\
\hline Married & 101 & 48 \\
\hline Single & 63 & 30 \\
\hline Divorce/ widowed & 47 & 22 \\
\hline \multicolumn{3}{|l|}{ Religion } \\
\hline Christian & 132 & 63 \\
\hline Moslem & 79 & 37 \\
\hline \multicolumn{3}{|l|}{ Husband education } \\
\hline No formal & 22 & 22 \\
\hline Primary. & 29 & 29 \\
\hline Middle/ JSS & 33 & 33 \\
\hline Secondary/Tech & 17 & 16 \\
\hline \multicolumn{3}{|l|}{ Education } \\
\hline None & 74 & 35 \\
\hline Primary. & 61 & 29 \\
\hline Middle/ JSS & 49 & 23 \\
\hline Secondary / T ech & 27 & 13 \\
\hline \multicolumn{3}{|l|}{ Employment status } \\
\hline Employed & 153 & 73 \\
\hline Not employed & 58 & 27 \\
\hline \multicolumn{3}{|l|}{ Occupation } \\
\hline Farming & 70 & 46 \\
\hline Trading & 64 & 42 \\
\hline Civil/public servant & 18 & 12 \\
\hline
\end{tabular}

The mean age of the respondents was 36 years $(\mathrm{SD}=8)$ with majority of the women aged below 35 years $(55 \%)$. Forty eight percent of the women were married and $63 \%$ were Christians. Among those married, majority of their husbands had some form of formal education with $22 \%$ having none. Thirteen percent of the women had schooled to the secondary level and 35\% had no formal education. One hundred and fifty-three representing 73\% were employed and the most cited occupation was farming (70, $46 \%$ ) as detailed in table 1.

\subsection{ART Defaulting Rate}

As detailed in figure 2 the total defaulting rate among the wo men was $21 \%$ (45 out of 211 respondents). At Nyinahini, 28 out of the total of 121 had defaulted ART. Defaulting was higher among respondents from Nyinahini as compared to Ejura (23\% vrs 19\% respectively). 


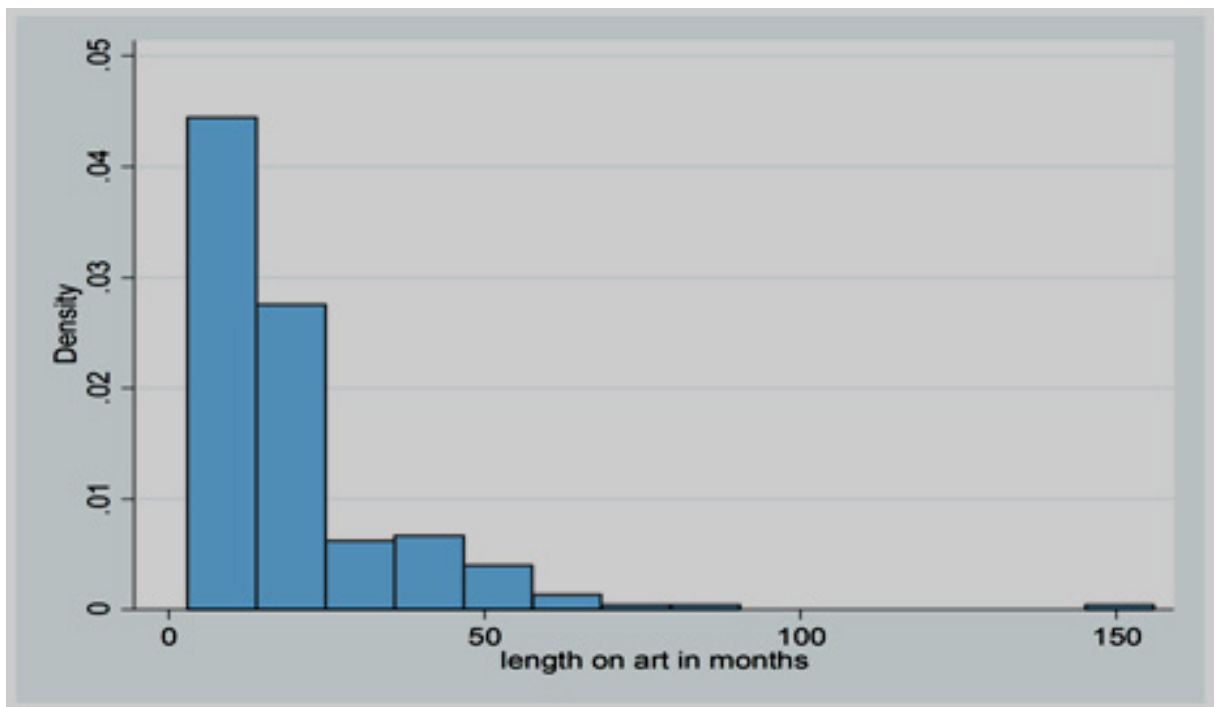

Figure 1. Number of months respondents are on ART

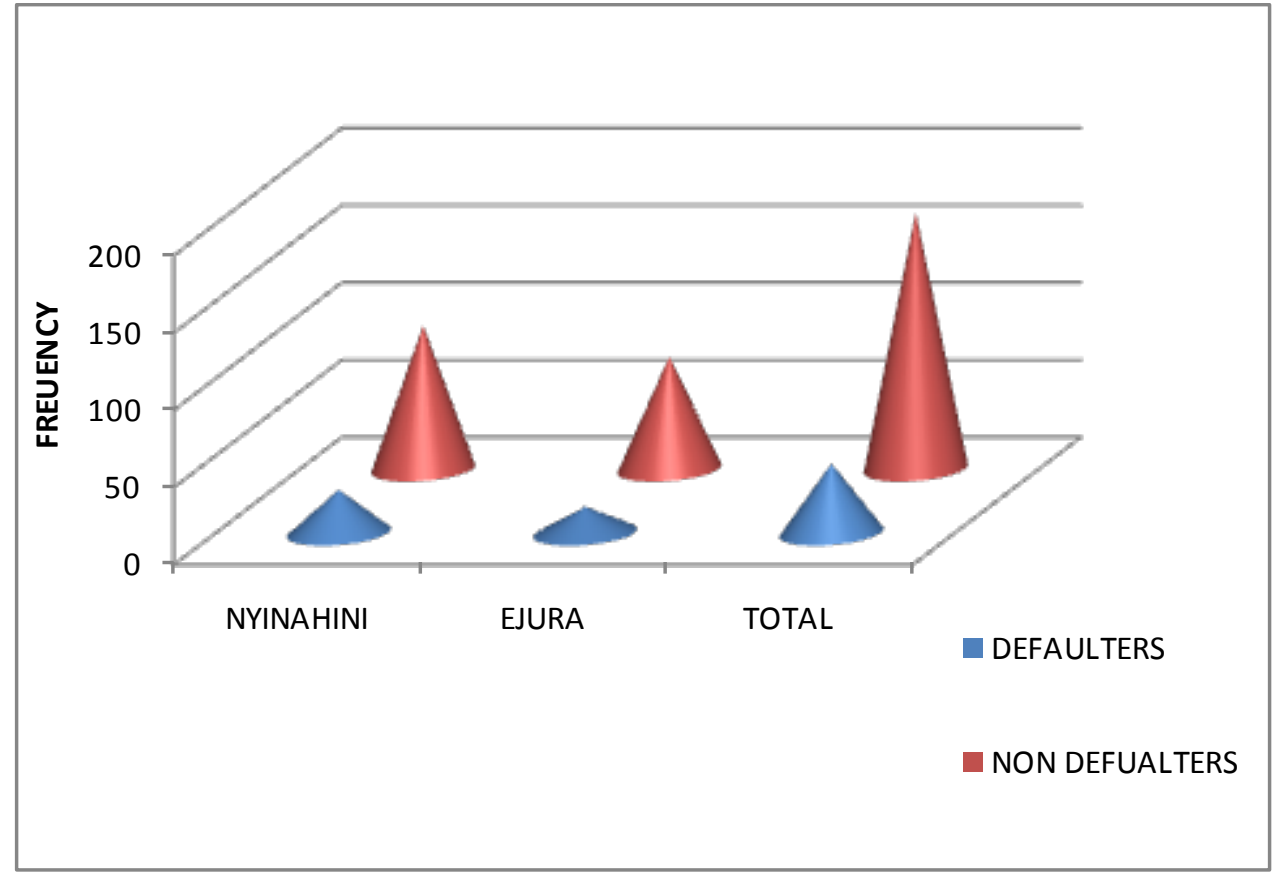

Figure 2. ART defaulting rate

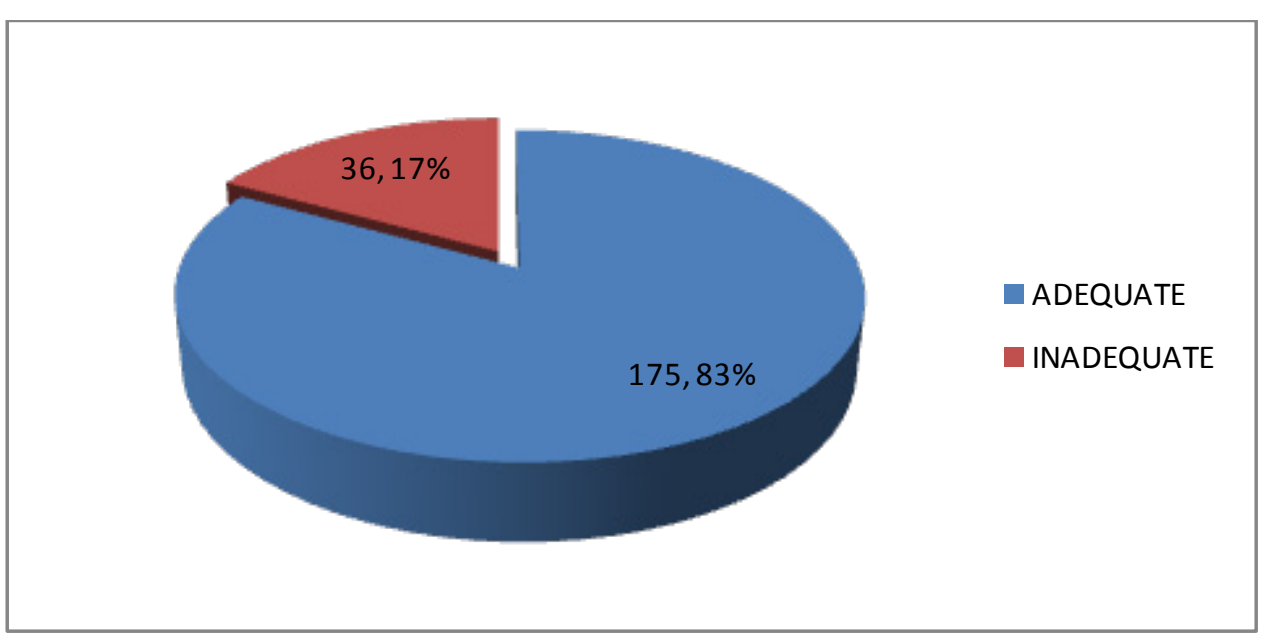

Figure 3. summary of knowledge level on PMCT 


\subsection{Knowle dge on PMTCT}

Table 2 gives a summary of the responses of the women on their knowledge about MTCT. Seventy-two percent of them knew that HIV/AIDS could be transmitted through MTCT About $15 \%$ of the women exhibited no knowledge about the possibility of transmission of HIV from mother to the baby. The women who had knowledge of MTCT indicated that this could be intrauterine (88\%), delivery $(69 \%)$ and through breastfeeding (82\%). Thirty-six percent however had no knowledge on the mode of MTCT of HIV.

Table 2. Frequency Analysis of Knowledge about HIV/AIDS, MTCT and ART

\begin{tabular}{|c|c|c|}
\hline Variable & Frequency & Percentage \\
\hline \multicolumn{3}{|l|}{ Mode of spread of HIV/AIDS } \\
\hline Sexual intercourse & 209 & 99 \\
\hline Blood transfusion & 184 & 87 \\
\hline Using unsterile instrument & 192 & 91 \\
\hline Mother to child transmission & 152 & 72 \\
\hline Spiritual & 46 & 22 \\
\hline \multicolumn{3}{|l|}{ Mother to child transmission } \\
\hline Possible & 190 & 90 \\
\hline Impossible & 6 & 3 \\
\hline Don’t know & 15 & 7 \\
\hline \multicolumn{3}{|l|}{$\begin{array}{l}\text { Mode of spread of mother to } \\
\text { child }(n=196)\end{array}$} \\
\hline In the womb (intraut erine) & 172 & 88 \\
\hline During delivery & 135 & 69 \\
\hline Through breastfeeding & 161 & 82 \\
\hline $\begin{array}{l}\text { Anrougn breastreeding } \\
\text { Don't know }\end{array}$ & 27 & 36 \\
\hline \multicolumn{3}{|l|}{ MT CT preventable? } \\
\hline Preventable & 133 & 63 \\
\hline Not preventable & 55 & 26 \\
\hline Don’t know & 23 & 11 \\
\hline \multicolumn{3}{|l|}{ Means of PMT CT } \\
\hline Giving ART & 160 & 76 \\
\hline Avoiding breast feeding & 152 & 72 \\
\hline $\mathrm{C} / \mathrm{S}$ delivery & 61 & 29 \\
\hline \multicolumn{3}{|l|}{ Antiretroviral are drugs } \\
\hline To cure HIV & 82 & 39 \\
\hline To prolong lives & 169 & 80 \\
\hline \multicolumn{3}{|l|}{ To prevent death from } \\
\hline HIV/AIDs & 150 & 71 \\
\hline \multicolumn{3}{|l|}{ To prevent transmission } \\
\hline to baby & 65 & 31 \\
\hline $\begin{array}{l}\text { Works effectively with } \\
\text { optimal adherence }\end{array}$ & 207 & 98 \\
\hline
\end{tabular}

Knowledge on ART and PMTCT was adequately higher among the respondents. Ninety percent knew that MTCT was possible and $82 \%$ knew this could be through breast feeding. Clients' high knowledge on PMTCT and ART as reported in this study could also be partly due to the institution of counselling as part of the programme, where new clients are taking through the benefits of adhering to ART, the problems associated with defaulting ART and issues relating to PMTCT. This was evident in their responses that ART works with optimal access (98\%). The respondents who have achieved optimal access cited the need to adhere to ensure effectiveness of the drug as a reas on for always coming for ART appointment. Overall, knowledge of the cause of HIV/AIDS, modes of transmission, and importance of ART adherence was good in a study in South Africa[12].

The result was also consistent with a recent study[7], where knowledge on PMTCT was high among the women studied. In that study, majority of the mothers knew that it was possible to reduce the risk of transmission during pregnancy $(82.2 \%)$ and the breastfeeding period $(71.6 \%) .88 \%$ knew vertical transmission is preventable and $85 \%$ knew it can be done through giving ÄRT.

Majority $(63 \%)$ of the women correctly indicated that MTCT of HIV is preventable and could be done through giving ART to the nursing mother, avoiding breastfeeding, and opting for caesarean delivery. The views of the respondents about the ART were also investigated. Almost all the wo men (98\%) in the study correctly knew that ARTs work effectively with optimal adherence to it. About $80 \%$ of the respondents are aware that ART are drugs to prolong the lives of people living with HIV once they do not default.

In the qualitative study, most of the respondents had good knowledge on PMTCT and how ARVs work. Their views about the benefit of ART had considerable influence on their use of the drug. Most of the women stated that, the drugs makes the virus weak and unable to attack their immune system. So me said the drug acts like a cup to cover them and prevent them from acting so one needs to take it always to keep them where they are, and she can live as long as God wants them to.

One client form Ejura reported:

"When I was first coming I was carried like a mat. Now look at me. No one even realize I am sick. The drug has helped me so I will never default" (never defaulted).

Another client from Nyinahin i reported:

"The drug cannot cure the HIV. It suppresses the virus so you always need to take or the virus will become strong again" (never defaulted).

Although at least $72 \%$ of the respondents are aware each of the possible causes of HIV/AIDS, some still have negative perception about the causes of HIV/AIDS. About (22\%) thought HIV is caused by bewitchment and have been going to prayer camps for spiritual intervention.

One patient reported:

"When the virus was first detected in my blood, I brought all my children and none had it. My husband also hasn't got it. So I believe I got it through spiritual means because I have never committed adultery" (defaulter).

Knowledge level on PMTCT and ART was quite high among the respondents. One hundred and seventy-five women constituting $83 \%$ had adequate knowledge on PMTCT and ART. Comprehensive knowledge was measured as correctly identifying the modes of HIV transmission, possibility of PMTCT, modes of MTCT, means of PMTCT, other related questions on ART and rejecting all misconceptions on spread of HIV. This was however consistent with the GDHS report 2008[9], which 
showed that only $28.3 \%$ of female respondents age $15-44$ had comprehensive knowledge about HIV and AIDS.

A cross-tabulation analys is indicated a significant positive association between respondents' knowledge level and defaulting of ART. Mothers with incomprehensive knowledge on ART were 2.5 times more likely to default ART $(\mathrm{OR}=2.5, \mathrm{p}=0.002)$. Other factors exerting an independent effect on MTCT include preterm delivery, rupture of membranes (every hour of membrane rupture increases the risk of infection by $4 \%$ ). Elective caesarean delivery before labour and rupture of the membranes reduces the transmission risk by approximately half[6],[19].

A bivariate analysis revealed a significant association between the knowledge level and the educational level of the women as shown in table 3. Comparatively, comprehensive knowledge level was higher among the women below 34 years as against those above $(88 \%$ vrs $74 \%$ ). HIV positive women with formal education were significantly almost two times more likely to have a comprehensive knowledge on PMTCT and ART (OR=1.9; $\mathrm{p}=0.003$ ). Negative perceptions about ART were associated with low education level in the study by[12]. The women whose husbands had formal education were also more likely to have comprehensive knowledge on PMTCT and ART as compared to those this no formal education ( $78 \%$ vrs $73 \%$; $\mathrm{OR}=0.23$ ).

Table 3. Influence of Age and Education on Knowledge Level

\begin{tabular}{ccccc}
\hline & \multicolumn{2}{c}{ Knowledge level } & \multirow{2}{*}{ OR } & p-value \\
\cline { 2 - 3 } Co-variates & $\begin{array}{c}\text { Compreh } \\
\text { ensive }\end{array}$ & $\begin{array}{c}\text { Incompreh } \\
\text { ensive }\end{array}$ & $(95 \% \mathrm{C})$ & \\
\hline Age & & & & \\
$<34$ & $95(88)$ & $21(18)$ & 0.71 & \\
$>34$ & $70(74)$ & $25(26)$ & $\begin{array}{c}0.12, \\
0.91)\end{array}$ & 0.061 \\
& & & & \\
Husband & & & & \\
education & & & 0.23 & \\
Formal & $62(78)$ & $17(22)$ & $(0.11$, & 0.120 \\
N0- formal & $16(73)$ & $6(27)$ & $0.35)$ & \\
& & & & \\
Education & & & 1.90 & \\
Formal & $56(76)$ & $18(24)$ & $(1.26$, & 0.003 \\
Non-formal & $109(80)$ & $28(20)$ & $2.31)$ & \\
\hline
\end{tabular}

Consistent with in study in 1999[2], 2006[8], 2007[17] and a recent study in 2010[4] knowledge level was significantly associated with the use of ART $(p=0.000)$.

A lower level of general education and poorer literacy may impact negatively on some patients' ability to adhere, while a higher level of education has a positive impact. Increased level of education was associated with increased level of knowledge on PMTCT and ART. Knowledge level was higher among those below 34years and those whose husbands have formal education. Mothers with formal education were significantly more likely to have adequate knowledge of PMTCT and ART $(\mathrm{OR}=1.9 ; \mathrm{p}=0.003)$. Th is is consistent with the finding of reference[2], which asserted that a lower level of general education and poorer literacy may impact negatively on some patients' ability to adhere, while a higher level of education has a positive impact

This could be due to the fact that most sensitization media including bill boards, TV adverts and leaflets as part of the social marketing campaign strategies are conducted in English language making it difficult for the illiterate in society to understand.

\section{Conclusions}

It is evident that respondents' knowledge level plays an important role in their access to ART which supports the findings of [14]. Superstition with respect to the causes of HIV is still high among the respondents. This could be attributed to the fact that, education on HIV given to these wo men is not targeting misconceptions about the etiology of the disease. However, mothers' educational level is a key determinant of their knowledge on HIV/AIDS, ART and PMTCT.

Generally the respondents understand that is effective and prolongs life. In addition they are also aware that poor adherence may result in viral resistance. This conforms to the result of a study by[18]. Furthermore, majority of the respondents are aware that MTCT was possible and could be through Mother's breast to the child during breast feeding process. Hence they are likely to accept any measures that would prevent this mode of transmission provided they can afford it and there is no stigma attached to it. The study revealed that counselling at the ART centre is very important in ensuring the respondent regularity at the ART centres to pick their medications [13].

The facility and community based educational interventions should therefore be scaled up and should be designed to be acceptable to both the literate and illiterate in the society. This must also seek to demystify the scientific nature of the disease and clear all misconceptions and possible thoughts of spirituality in the etiology of the disease. Social marketing campaigns should also be developed and targeted at improving women literacy on their health issues and getting more women to test for HIV in order to incorporate them into PMTCT programmes. Further research however needs to be conducted to ascertain the facility and community based factors that influence the wo men's knowledge on ART and PMTCT.

\section{ACKNOWLEDGEMENTS}

The authors wish to recognize the support of Prof. E.A. Addy, Dept of Community Health, Kwame Nkrumah University of Science and Technology. We are also grateful to our research assistants for their assistance. Finally, we would like to appreciate the support of the management and staff at the ART centre at Ejura and Nyinahini as well as all participants for their cooperation and enthusiasm in this study. 


\section{REFERENCES}

[1] Addo, V., "Pregnant Women's Knowledge of and Attitudes to HIV Testing at KATH". Ghana Medical Journal, Vol. 3 no. 92, pp.31-33, 2005.

[2] Catz. S. T. Heckman, A. Kochman, "Adherence to HAART therapy among older adults living with HIV disease" in proceedings of the Fourth International Conference on the Biophysical Aspects of HIV infection, Ottawa, 1999.

[3] Cheluget, B G Baltazar, P Orege, M Ibrahim, L H Marum, J Stover, "Evidence for population level declines in adult HIV prevalence in Kenya", BMJ Journals, Sex Transm Infect vol.82 pp.i21-i26, 2006

[4] Duff, P., Kipp, W., Wild, T. C., Rubaale, T., Okech-Ojony, J., "Barriers to Accessing Highly Active Antiretroviral Therapy by HIV Positive Women Attending an Antenatal Clinic in a Regional Hospital in Western Uganda". Journal of the International AIDS society, pp. 4-9, 2010.

[5] Dzokoto Agnes, "National Report on the Progress of the United Nations General Assembly Special Session (UNGASS) Declaration of Commitment on HIV and AIDS", Ghana AIDS Commission, 2008.

[6] European Collaborative Study, "Fluctuations in symptoms in HIV infected children: the first 10 years of life", Pediatrics 2001 vol.108, pp.116-122, 2002

[7] Eli Fjeld Falnes, ThorkildT ylleskär, Marina Manuela de Paoli, Rachel Manongi, Ingunn MS Engebretsen, "Mothers Knowledge and utilization of prevention of mother to child transmission of HIV in Northern Tanzania". Biomed Central, Journal of International AIDS Society, vol.13, no.36, 2010

[8] Fisher, J, Fishe, W., Amoco, R.K, \& J.F Hamann (2006). An Information- Motivation- Behavioural Skills Model of adherence to Antiretroviral Therapy, Health Psychology, 25 (4): 462-473

[9] Ghana Aids Commission., "Ghana's progress report on the United Nations General Assembly special session: declaration of commitment on HIV and AIDS", Ghana Aids Commission, 2010.
[10] Ghana Health Service, "Ghana Demographic and Health Survey 2008 Report”, Ghana Health Service, 2009.

[11] H. Liu, et al., "A comparison of multiple measures of adherence to HIV protease inhibitors", Annals of Internal Medicine, no.134, pp.968-997, 2001.

[12] Nachega JB, Lehman DA, Hlatshwayo D, Mothopeng R, Chais s on RE, Karstaedt AS. "HIV/AIDS and antiretroviral treatment knowledge, attitudes, beliefs, and practices in HIV-infected adults in Soweto, South Africa". J Acquir Immune DeficSyndr Vol. 38, no. 2, pp. 196-20, 2005

[13] National AIDS Control Programme, "An overview of HIV and AIDS in Ghana: Current Situation, Projections and Interventions", Ghana Health Service/ National AIDS/STI control Programme, 2010.

[14] National AIDS Control Programme, "National HIV Prevalence and HIV/AIDS Estimate report", National AIDS control Programme/ Ghana Health Service, 2010.

[15] National AIDS Control Programme, "National HIV Prevalence and HIV/AIDS estimate report". National AIDS control Programme/ Ghan a Health Service, 2011

[16] .Nemes, M.B,.Carvalho H.B, Souza, M.F.M. "Antiretroviral therapy adherence in Brazil”, AIDS 18, Suppl 3, pp.S15-S20, 2004.

[17] Ramchandani SR, Mehta SH, Saple DG, Vaidya SB, Pandey VP, Vadrevu R, Rajasekaran S, Bhatia V, Chowdhary A, Bollinger RC, Gupta A. "Knowledge, attitudes, and practices of antiretroviral therapy among HIV-infected adults attending private and public clinics in India”. AIDS Patient Care STDS. Vol. 21, no.2, pp.129-42, 2007

[18] Safren, S.A..Kumarasamy N,. James R,.Raminani S,. Solomon S, Mayer K.H., "ART adherence, demographic variables and CD4 outcome among HIV positive patients on antiretroviral therapy in Chennai, India", AIDS Care, vol.17, no.7, pp.853-862., 2005.

[19] Jimmy Volmink and Ben Marais, "HIV: Mother-to-child Transmission", Pubmed, Clinical evidence, 2007.

[20] UNAIDS. “'World AIDS Day Report”. November 2011

[21] Wenger N,. Gifford A, Liu H., Chesney M., C. Golin, "Patient characteristics and attitudes associated with HAART adherence", 6th Conference on Retroviruses and Opportunistic Infections, Chicago, Abstract 981, 1999. 